\title{
Dissimilar Discourses: The Realism of Amis's Conversations in Lucky Jim
}

John K. Eastman

E.O.I. Alicante

\begin{abstract}
This paper attempts an objective analysis of some lexico-grammatical features in conversations between Jim Dixon and the principal characters of Lucky Jim. The aim is to show that these relate closely in several respects to Bernstein's codes. The method of analysis is empirical, verifiable and replicable, and can claim some scientific rigour. On the measures adopted, academics and friends in the novel are found to have consistently different profiles. Social class, code and tenor appear to have interacting rather than causal relationships, suggesting a more complex language system than Halliday proposed.
\end{abstract}

Kingsley Amis invests his characters with different varieties of English in their conversations. Most memorable perhaps are those that involve graphological variation, like Patrick Standish's drunken discourse in Take a Girl Like You, or Dixon's desperate imitation of a hypercorrected dialect (Farteskyaw) in Lucky Jim.

Amis talked about his method of capturing lifelike conversation on a B.B.C. radio programme:

... trying to catch someone's tones, hearing them in your head and then trying to put them on paper is ... very useful to the reader. ... the way people talk ... tells an awful lot about what kind of person they are, and if you think you can hear the character talking, it's much easier to identify with that person....

We argue that in Lucky Jim, Amis succeeds in doing just this, namely giving his characters individual registers which also reflect their personalities to some degree. Furthermore, we hope to show that the variation in Amis's dialogue is realistic at an objective level and at the same time is consistent within groups of characters according to their social class and the type of relationship they have with Dixon.

Several writers, including Burton, Page and Turner, ${ }^{2}$ have argued that written conversation does not usually include the hesitation phenomena, repetitions and false starts of real life, and can therefore not be objectively regarded as realistic. However, we may argue that while such features undoubtedly exist, our memory of them is weaker, and we tend to recall the substance of a message rather than the paralinguistic features of its delivery. Therefore the written representation of spoken discourse may 
strike us as subjectively realistic without necessarily including hesitations, false starts and the rest, the other objective realities of speech production. Where these do intrude on the interlocutor, i. e. they are salient to the character, and are intended by the author to impinge on the reader, they should of course be included in the written discourse, if the writer is to transmit his realism to the reader.

Examples of these phenomena can be found in some of Professor Welch's conversations with Dixon:

I've been wondering if you'd care to come round next weekend for the ... weekend. ${ }^{3}$

Not too academic, and not too ... not too ... Do you think you could ...? (p. 17).

Oh, there are a few here, yes, without ... just long shots, really ... If there aren't any, then you'll just have to use your own ... your own ... The chapter titles will probably help you (p. 173).

Dixon, too, is made to show an example of a false start, reflecting his embarrassment at being found in a compromising situation:

We're just ... I'm just ... I was just getting rid of this table, as a matter of fact (p. 74).

At this level then, Amis shows us that he does include real-life paralinguistic events in written dialogue, revealing the completeness of what Mellors ${ }^{4}$ called his "Piano-tuner's ear".

At another level, however, we find him reflecting language-use according to social class or education. As Bernstein would later show, ${ }^{5}$ the working-class strata tend to use a group-oriented "Restricted Code" (RC), while the middle classes have available to them both RC and an individual-oriented "Elaborated Code" (EC). Pride outlined one of Bernstein's earlier statements on the details of RC:

... [ $[\mathrm{RC}]$ is said to be very much the more predictable in every respect, characteristically displaying short and unfinished and grammatically simple sentences, active yoice, little use of subordinate clauses, limited use of adjectives and adverbs and conjunctions. ${ }^{\circ}$

Such clearly defined features invite use as measures of dialogue. We can predict that Amis's working-class people will display these features to a high degree, and other classes will show them to a lesser degree. If the predictions hold, we can claim that Amis's dialogue is true to life. The analysis is therefore largely limited to lexicogrammatical features of the text.

The conversations between Dixon and each of the principal characters were amalgamated (disregarding field of discourse) and then separated into the contributions by Dixon and each character. The features mentioned were then counted, and to make comparison between the characters possible, the raw data were expressed as percentages of the total number of sentences uttered by each character, the sentence being used as basic unit, since it is specified by Bernstein. This produces the following measures:

1. Simple: sentences with one main verb;

2. Complex: sentences with one or more subordinate clauses;

3. Complete: grammatically complete sentences; 
4. Elliptical: grammatically incomplete sentences, whether initially or finally;

5. Adjectives in attributive position other than demonstratives, possessives and numbers, which are basic to any discourse;

6. Adverbs expressed as one word only; adverbials not included;

7. Conjunctions: subordinating only.

These measures produce four scales:

1 and 2 combine to give a measure of complexity

3 and 4 give a measure of ellipsis

5 and 6 yield a measure of richness of speech

and 7 profiles another sort of complexity

$$
\begin{aligned}
& \mathrm{C} ; \\
& \mathrm{E} ; \\
& \mathrm{R} ; \\
& \text { Conj }
\end{aligned}
$$

Halliday ${ }^{8}$ recognizes three main determinants of register; (1) code, which is a sociological phenomenon, and (2) the semantic aspect of adult language which combines with (3) social context. Within social context there are mode, field and tenor. In the analysis which follows, mode is a constant, being (written) speech throughout; field of discourse is effectively neutered by the amalgamation of several dialogues (although we occasionally turn to subject-matter to seek explanations). Tenor of discourse remains, reflecting principally the status differences between Dixon and his interlocutors.

Now status differences will affect speech chiefly in terms of formality of grammatical structure, and might be reflected on our Ellipsis scale. Joos ${ }^{9}$ proposed a scale with five degrees of formality: frozen, formal, consultative, casual and intimate. Corder ${ }^{10}$ and Turner (op. cit.) among others have expressed dissatisfaction with this scale, but no successor seems to have emerged, possibly because it is used to refer to

forms of language . . . associated with certain modes . . . and . . to the degree of respect that is shown to the person ... addressed. 11

It might be more fruitful to consider interpersonal relationships as bringing about certain styles of speech, rather than simply nominating, as Joos did, certain different styles, which are only the result of speech situations. The principal ingredient in any status relationship is the presence or absence of status differences. Where status is absent or unimportant, we may talk of friendship, which can range from intimate through neutrality (zero friendship) to 'negative' friendship, or dislike and hatred. As these last make the term 'friendship' something of a misnomer, we shall use the term throughout in inverted commas -"friends."

Where status differences do exist, we may distinguish explicit status, as for example exists between superior and subordinate in an organization or institution, and implicit status, where the 'subordinate' does not work directly for the 'superior,' as between a public servant (taxi-driver, bus-conductor, railway porter) and a member of the public. Of course, such implicit status differences may involve social class differences; where such differences do not exist or are ignored by the participants, the relationship effectively falls somewhere on the 'friendship scale,' possibly around the neutral point.

If Amis's conversations are realistic, they should reflect differences both in terms of Bernstein's codes and in terms of the degree of formality of Dixon's relationships, whether institutional or 'friendly.' In the results given below, Dixon's conversations with taxi-driver, bus-conductor and railway porter were too short to yield meaningful 
data, and have been combined as "Public Servants." These are grouped under institutional relationships, for these characters bear an implicit status-relationship with Dixon as a member of the public. His relationships with Professor Welch and the student Michie are status-explicit, the former being his superior, the latter having a supposedly inferior institutional relationship with Dixon.

The values on our scales for the principal characters, expressed as percentages of all utterances made by them, are as follows:

Institutional relationships

E C R Conj

Public Servants

Professor Welch

75

20

15

0

6

Michie

$49 \quad 49$

38

"Friendly" relationships

E

$\begin{array}{lll}49 & 70 & 19\end{array}$

Academics:

Beesley
Margaret

27
8

Non-academics: Carol

Christine

Bertrand

Catchpole

$\begin{array}{llll}14 & 56 & 28 & 32 \\ 9 & 41 & 18 & 25 \\ 11 & 48 & 32 & 40 \\ 14 & 55 & 24 & 24\end{array}$

These data are better visualized in the form of profiles, as in figures 1 to 4 below.

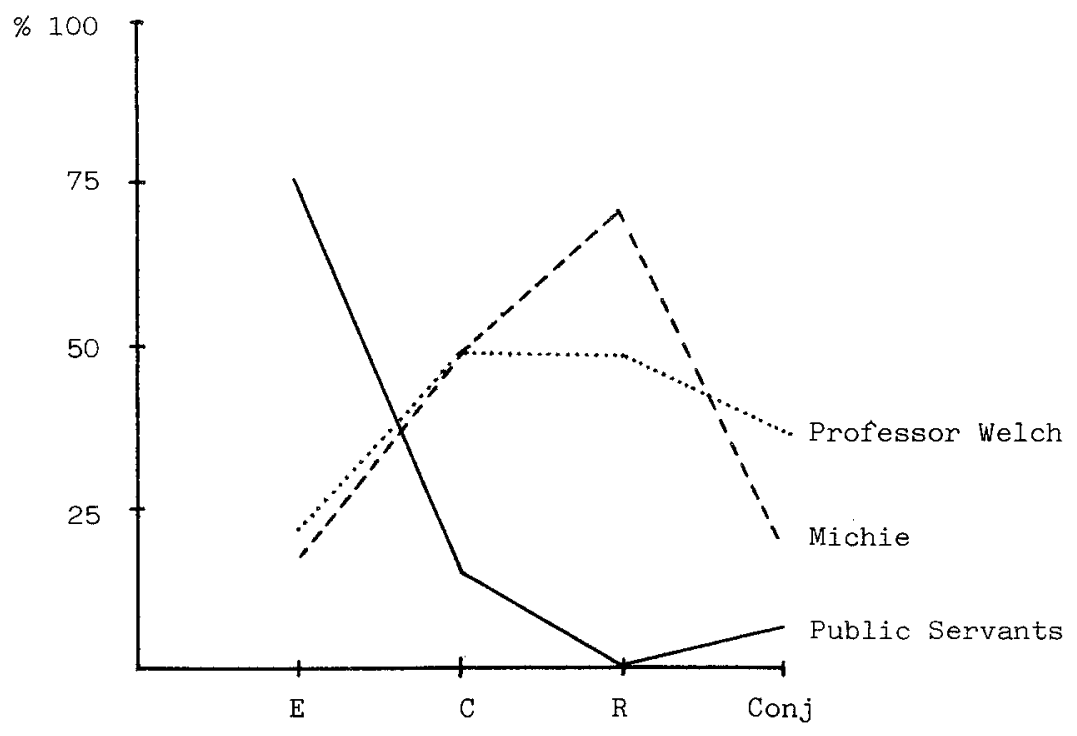

Fig. 1: Profiles of the characters having an institutional (status) relationship with Dixon on the four measures 
The outstanding finding here (fig. 1) is that the Public Servants have extremely high Ellipsis and zero Richness, fitting Bernstein's observations of RC speakers very well indeed. For example, only one elided passive can be found in their combined conversations:

Not allowed to draw petrol except from our own garage (Taxi-driver, p. 133).

Initial ellipsis is very common in the Public Servants' contributions:

[Have you got a] Train to catch? (p. 243)

[You're a] Bit early, aren't you? (p. 245)

as well as initial and final ellipsis:

[There's] Not enough petrol [to take us as far as you want to go] (p. 133).

The Public Servants' profile is virtually the inverse of Michie's and Professor Welch's, whom we accept as EC speakers from their class origins and education. Michie's profile shows far higher Richness, which may be put down to the fact that he mainly discusses topics related to academic work, and which require elaboration. Amis also tells us that he comes from an upper social class. Professor Welch's profile, on the other hand, is high in the Conjunction measure, which reflects his absentmindedness and long, rambling sentences. They are both low on Ellipsis, which shows their tendency to explicitness (another EC characteristic), as well as the relatively formal tone of their conversations. Formality and field may also account for their relatively high Complexity scores.

The evidence so far, then, supports our contention that Amis really did achieve realism.

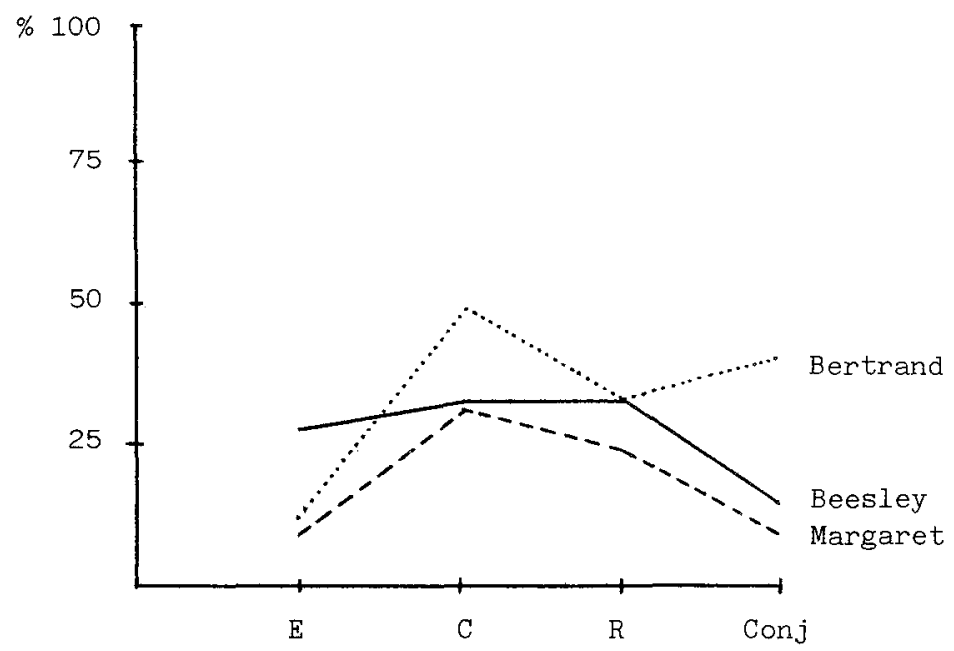

Fig. 2: Profiles of one non-academic (Bertrand) and two academic 'friends' on the four measures. 
The other profiles fall into two groups; the academic and the 'friendly.' They are characterized by 'humped' or 'zig-zag' shapes respectively. Humpiness is due to R scores being relatively higher than Conj scores among all the characters who are academics (Professor Welch, Michie, Beesley and Margaret), while non-academics (Dixon's 'friends' - Carol, Bertrand, Catchpole and Christine) are comparatively low in $\mathrm{R}$, giving zig-zag profiles. The significance of this may be no more profound than that informal situations, being more relaxed than institutional ones, demand less richness of speech. More is taken for granted. Or that the discourse topics, being more mundane, do not require it. However, Amis here achieves a consistent difference in register between two sociologically distinct groups.

Among the academics, Professor Welch and Michie (fig. 1) show the highest $\mathrm{R}$ scores, while Beesley's and Margaret's profiles (fig. 2) are less pronounced in this respect. The lower $\mathrm{R}$ scores of the latter two may reflect the more 'friendly' relationships they have with Dixon; we would expect rather less richness of speech from 'friends,' and more in more formal institutional relationships. Thus, in Amis at least, Richness of speech is highest in the most formal relationships (with the academics, Professor Welch and Michie), lowest in 'friendly' relationships (with Carol, Bertrand, Catchpole and Christine) and intermediate in relationships where 'friends' and education (academic-ness) coincide. We cannot decide, on these measures alone, whether field or relationship play a larger role in lower $\mathrm{R}$ scores, but we note that as well as the zig-zag and humped profiles being consistently repeated, there is also a consistent relationship between the different categories of relationships, and these agree with our intuitions.

Of the EC speakers, Beesley, an academic, has the highest E score, usually from initial ellipsis:

[A] Spot of good news. .. (p. 31).

[I] Doubt it, for October (p. 31).

[There's] Something that'll interest you here, Jim (p. 171).

[It] Looks as if his new review. . (p. 171).

and we may hazard that Amis adopted this (from real-life?) as a means of distinguishing Beesley's register from other "friends" registers.

Margaret, we are told, is neurotic, and her profile is notable for its extremely low $\mathrm{E}$ and Conj scores. Her speech is largely grammatically complete, and formed of short sentences. Indirect evidence supporting the notion that mental instability leads to the simplification of speech comes from a study referred to by Robinson. ${ }^{12} \mathrm{He}$ reports that suicide notes showed just such simplification effects. This simplification would lower her $\mathbf{R}$ score also.

Bertrand (fig. 2) also has a low E score, but in his case this appears to be related to the emotionally-charged scenes he plays out with Dixon, a simplification effect not unrelated to the desperation of suicide. His higher Conj score may be due to his tendency to explain things to Dixon. On the 'friendship' scale he begins his relationship with Dixon at the dislike point but rapidly moves to enmity.

Christine's E score (fig. 3) is as low as Margaret's; however, Amis says she may have been to elocution school (a predominantly middle-class thing to do, therefore marking her as an EC speaker) and speaks in a "school-marmy" way, which suggests that Amis has in mind a person who speaks 'correctly' and whose grammar is not as relaxed as that of Dixon's other friends, thus decreasing the amount of ellipsis she 
uses. Her $\mathbf{R}$ score is also low as compared with other 'friends', which may reflect her relative youth, her lower level of education (she is a shop-assistant), or simply Amis's feel for youthful discourse.

Catchpole (fig. 3) begins the story at the dislike point on our 'friendship' scale, as Dixon has been lead to believe that he had jilted Margaret, precipitating her (faked) suicide attempt. When Catchpole at last appears in person, Dixon learns that

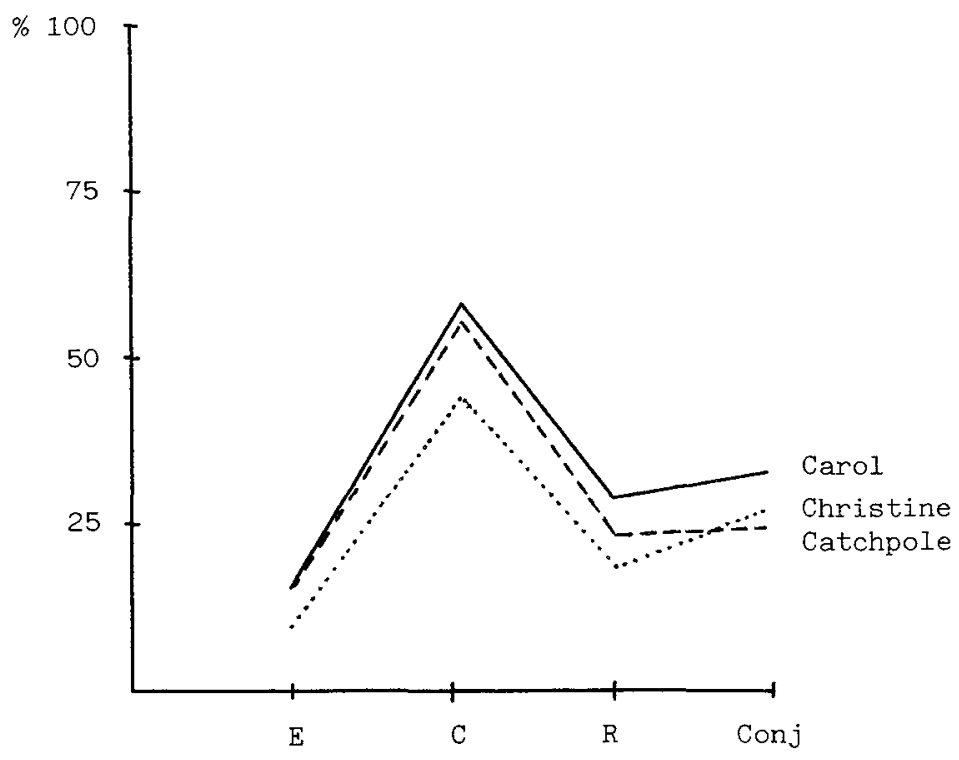

Fig. 3: Profiles of three 'friends.'

this is all a fabrication, and we suppose that Catchpole moves to the neutral point on the scale. There is, however, little difference between his profile and Carol's, who is Dixon's closest friend. This similarity may be due to the similarity of their functions in the novel -that of giving Dixon information.

Turning to Dixon's contributions to these conversations, (fig. 4) we find that his linguistic response to the public servants is to echo their Richness (zero), and lower his Conjunction rate, i. e. he adopts two features of RC. As if to compensate, however, his C (complexity) score is very high compared with other EC speakers. We are justified in asking ourselves what our response to $\mathrm{RC}$ speakers is, and perhaps permit ourselves to speculate that in Dixon's response, we have an example of Amis's own.

$\begin{array}{lllll}\text { Dixon's contributions with } & \text { E } & \text { C } & \text { R } & \text { Conj } \\ \text { Public servants } & 24 & 71 & 0 & 5 \\ \text { Academics } & 12 & 29 & 22 & 11 \\ \text { Academic friends } & 5 & 28 & 17 & 13 \\ \text { Friends } & 15 & 31 & 22 & 21\end{array}$


His profile with academics just achieves humpiness, but then he is, after all, not an academic. His profiles with friends, academic or otherwise, are not quite zig-zags. In other words, the patterns found in academics and 'friends' do not appear with such clarity in the central character. That is to say, Dixon's registers are not so clearly delineated as the other characters are. To explain this finding, we may surmise that Amis is presented with less of a problem with the other characters, because they present only one facet to us in their discourse -they are linguistically two-dimensional. Dixon, on the other hand, must be multi-faceted, must interact with them all, but simultaneously the author must preserve an integrity of character which should reflect in his discourse. We might alternatively suggest that Amis based each of his characters on specific persons he knew and whom he could hear 'talking,' while Jim Dixon is more purely fictitious or a combination of several persons. That said, however, we note the relative similarity of the registers recorded with the three different categories of acquaintances, which suggests that Amis finally preferred to achieve a good measure of integrity of character rather than attempt subtle variations of code.

As we have seen, Amis himself claims to write conversations using his mind's ear, but we do not for one moment consider that he based them on the linguistic considerations expounded here. It is nonetheless quite startling that we should find such consistency in his portrayal of EC speakers as instanced by the humped and zigzag profiles, and this provides more support for the realism we claim for his dialogues. While it shows internal consistency and intuitively appeals as right, however, for truly independent confirmation we require a similar analysis of real-life conversations between friends and academics in broadly similar situations. That Dixon's discourse does not quite show a zig-zag profile with friends gives some indication of the struggle which Amis may have had to find the right tenor for Dixon in different circumstances, while at the same time maintaining linguistic integrity in the character.

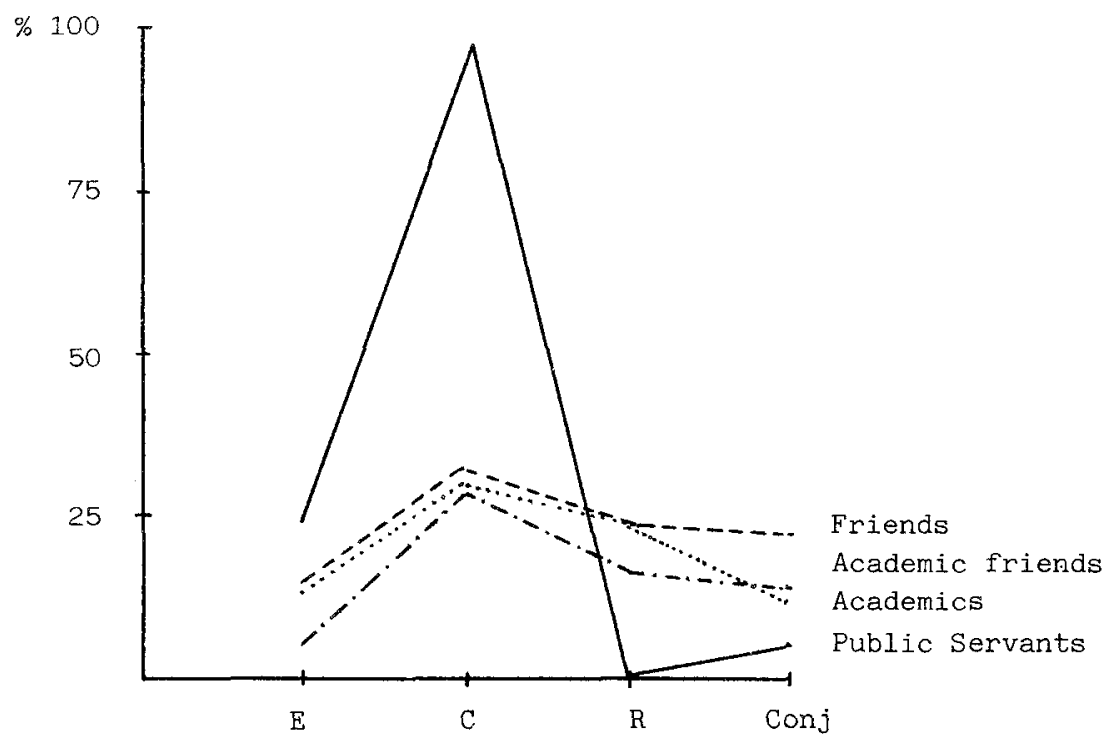

Fig. 4: Dixon's contributions to dialogues with characters in different role-relationships. 
The analysis we have carried out is not semantic and takes only incidental account of field of discourse. It examines some variables of language in situations of differing formality. The measures cannot be fully interpreted independently of the characters involved, it being crucial to know, for example, that the low $\mathrm{E}$ score in Margaret's case is due to her being neurotic, but in Christine's may be due to her elocution training.

This approach, or a similar one, appears to offer a viable means of comparing, contrasting and classifying individual register. Further studies would be necessary to show the degree to which fictional conversations approach real-life discourse. Above all, the interrelations of the contributing factors to given language varieties in various situations could be better understood.

Our findings suggest that lexico-grammar is related to register. Halliday ${ }^{13}$ recognizes the close relation of the semantic side of the adult linguistic system with register, but relates the lexico-grammar side only with social dialect. It may, however, be the social context which combines with the individual's reaction to any given situation which affects the choice of language. Thus we propose that the status/role relationships in Halliday's scheme (including the null status case of 'friendly' relationships), social contexts and lexico-grammar closely interact to affect register.

Likewise, Halliday's model does not contemplate the possibility of code-switching. We have found that Amis's Jim Dixon adopted a different code when conversing with Public Servants, albeit on only two of the measures. This means that the model should allow for EC speakers to switch to the Restricted Code when the situation calls for it, and should involve the lexico-grammatical aspect of the language system.

In general, it may be more true-to-nature to perceive of all sociological factors affecting and being affected by all the aspects of the individual's linguistic system, rather than having the limited number of causative connections that Halliday proposes.

\section{Notes}

1. B. B. C World Service programme Meridian, May 1984.

2. D. Burton, Dialogue and Discourse (London: Routledge \& Kegan Paul, 1980); N. Page, Speech in the English Novel (London: Longman, 1973); G. W. Turner, Stylistics (Harmondsworth: Penguin, 1973). to this edition.

3. K. Amis, Lucky Jim (Harmondsworth: Penguin, 1976), p. 17; all subsequent page references are

4. J. Mellors, "A Piano-Tuner's Ear," London Magazine, 14, 3 (1974), 102-106.

5. B. Bernstein, "Elaborated and Restricted Codes," Sociological Inquiry (Spring, 1966), number entitled Explorations in Sociolinguistics.

6. J. B. Pride, The Social Meaning of Language (London: O.U.P., 1971), p. 16.

7. The adjectives and adverbs included in this analysis are by definition superfluous to the basic message, permitting us to call this a measure of richness of speech; the conjunction measure should give an indication of the length of a character's sentences as opposed to their grammatical complexity. Only one passive was found among the RC speakers, and this measure has been omitted altogether.

8. M. A. K. Halliday, Language as Social Semiotic: The Social Interpretation of Language and Meaning (London: Edward Arnold, 1978).

9. M. Joos, The Five Clocks (The Hague: Mouton, 1962).

10. S. Pit Corder, Introducing Applied Linguistics (Harmondsworth: Penguin, 1973).

11. Halliday, op. cit. p. 224.

12. W. Robinson, Language and Social Behaviour (Harmondsworth: Penguin, 1972).

13. Halliday, op. cit., p. 69. 